\title{
Are we nearly there yet? A review of progress against CCS roadmaps in the UK
}

\author{
Clair Gough and Sarah Mander
}

Tyndall Centre for Climate Change Research, University of Manchester, Pariser Building

Sackville Street, Manchester, M13 9PL

Clair.gough@manchester.ac.uk

\section{Introduction}

5 years ago we held a stakeholder workshop (organised by the Tyndall Centre with Stuart Haszeldine on behalf of UKERC) in Edinburgh with the aim of developing a roadmap for CCS deployment in the UK. The workshop took as a starting point results from an extensive survey of expert opinion on the state of CCS technologies (Gough 2008) and produced roadmaps describing the short- and long-term views and the influence of externalities (Gough, Mander et al. 2010). In the meantime, other more recent roadmaps have been developed at a global scale by the IEA (International Energy Agency 2010), for Europe (EC CCS roadmap planned for release 3rd quarter of 2012), the US (DOE/NETL 2010), Scotland (Scottish Government 2010).

At the time of the workshop, in May 2007, the UK government announcement of the CCS demonstration competition was imminent and the focus was on bringing CCS through its demonstration era - with hope for the first plant to be operational by 2012. The competition announcement was delayed to the end of 2007 and the earliest date for a commissioning of a UK CCS plant revised to 2014. With a 3 year lead time and the earliest date for a firm investment decision on plant construction 2013 the first UK demo plant is now unlikely to be operational before $2016^{i}$

It is now 2012 and the original UK competition has failed to identify its first CCS demonstration plant, although the f1billion fund remains earmarked for CCS (Richards 2012) and selection criteria for a new competition are due to be announced this year. On the surface, this suggests little has progressed over the past 5 years- but how has the landscape changed? In this short paper we attempt to place CCS in the context of current mitigation challenges and consider progress against the milestones identified on our roadmap.

\section{Ever more challenging emissions reductions}

Since the roadmapping workshop in 2007, the UK's climate change policy has been evolving at a fast pace, with the scale of the emissions reductions required increasing. The UK Climate Act of 2008 adopts a cumulative emissions framework with an $80 \%$ target for reduction in $\mathrm{CO}_{2}$ (compared with 1990 levels) by 2050, specified across five year emission budgets (DECC 2008). The cumulative emissions framing prescribes the total $\mathrm{CO}_{2}$ that can be released by 2050 in order to remain within atmospheric $\mathrm{CO}_{2}$ concentration targets and requires that emissions reduce across the entire economy. If one sector is harder to decarbonise, or fails to meet its targets, other sectors have to do more to remain within the budget. The Act created an independent body, the Committee on Climate Change (CCC), which advises the government on the carbon budget for each five year budget period and reports annually to Parliament on the progress in meeting carbon budgets. The first three budgets were set by the CCC in December 2008 (CCC 2008); the second and third budgets were reduced in December 2010 to reflect the impact of the recession on emissions and the need for swifter reductions to remain within the budget in future years (CCC 2010). The inclusion of the emissions from international aviation and shipping in future budgets will increase the pressure on those other sectors with relatively easier opportunities for decarbonisation. 
A number of scenarios have been developed to describe how the UK may meet its carbon objectives which suggest that the future for CCS is not clear cut (e.g. CCC, 2010; DECC, 2010). The CCC proposes the decarbonisation of the electricity supply system by 2030 with a target carbon intensity for the grid of $50 \mathrm{~g} \mathrm{CO}_{2} / \mathrm{kWh}$ (the grid average in 2010 was $458 \mathrm{gCO}_{2} / \mathrm{KWh}$ (DECC 2011)). Given current capture rates of circa $90 \%$, this target would be challenging for a CCS plant unless either efficiency and capture rates can be improved, or co-firing of coal with biomass is introduced. Although the availability of sustainably sourced biomass remains a contentious issue, estimates suggest that a coal power station with $1-20 \%$ biomass co-firing and CCS could bring emissions below the $50 \mathrm{~g} \mathrm{CO}_{2} / \mathrm{kWh}$ target, with potential for negative emissions as the proportion of biomass increases (Gough and Upham 2011). Gas CCS has substantially lower residual emissions and may prove cost effective for both new build and retro-fit.

\section{CCS demonstration in the UK}

The competition for funding for the UK's first CCS demonstration plant was launched in November 2007 with the selected project to secure financial support (about $f 1$ billion) to test the technical and commercial viability of the technology along with the adequacy of the regulatory framework ${ }^{\mathrm{ii}}$. The competition was focused on post combustion capture from a coal fired power station. In November 2008, 4 companies pre-qualified for the competition: BP Alternative Energy International Limited; E.On UK plc.; Peel Power Limited and Scottish Power. The changing economic outlook, which reduced electricity consumption as well as impacting on the funds available for investment resulted in BP pulling out of the competition in $2008^{\text {iii }}$, followed by Peel Power in 2009iv. Difficulties in securing planning permission for new coal plants will also have had a part to play. In March 2010, funding was awarded to E.ON for the Kingsnorth project and Scottish Power for the Longannet project to support front end engineering and design (FEED) studies as part of the competition ${ }^{v}$. The winning project was to be decided on the basis of the technical studies but E.ON withdrew from the competition in October 2010 leaving Longannet as the only candidate ${ }^{\mathrm{vi}}$. The competition was finally laid to rest in November 2011 when negotiations between Department of Energy and Climate Change (DECC) and Scottish Power failed to reach agreement ${ }^{\text {vii }}$. Results from the two FEED studies are openly available via the DECCC website.

Whatever the future for CCS in the long term, establishing CCS demonstration projects remains important in order to resolve technical and cost uncertainties and better understand the potential role for CCS beyond demonstration (Gibbins and Chalmers, 2008). The Department of Energy and Climate Change is developing a process for bringing forward a further 3 demonstration projects which are open to coal and gas plant, and include post combustion, pre combustion and oxy fuel firing (Office of Carbon Capture and Storage 2011). Although the f1billion originally earmarked for the first demonstration project remains ring fenced to fund CCS (Richards (2012) there is as yet little detail as to the funding mechanism for projects 2-4, beyond a statement in the March 2011 budget that there would be no specific CCS levy (HM Treasury 2011).

Further funding for CCS is available through the European Commission's New Entrant Reserve (NER300) fund, targeted at innovative renewable and CCS technologies and financed by the sale of 300 million allowances under the EU Emissions Trading System. Successful projects, to be announced in 2012 , will secure funding for up to $50 \%$ of their relevant costs over a 10 -year period for CCS. The maximum number of projects in any Member State is three and by November 2011, six UK CCS ${ }^{\text {viii }}$ projects remain in the running ${ }^{\mathrm{ix}}$. Five of these UK NER300 applications are for new coal plant covering a variety of technologies; 3 are new pre-combustion (Don Valley, Kilingholme, Teesside), 1 is oxyfuel (Drax), 1 new post-combustion (Ayshire). The remaining scheme is a post-combustion retrofit gas plant (Peterhead CCGT). Of these, the Don Valley project in Yorkshire (formerly the Hatfield project) has already secured $€ 180$ milion funding from the European Economic Recovery 
Programme which has enabled National Grid to proceed with feasibility and design studies for a $\mathrm{CO}_{2}$ pipeline, with potential opportunities for serving a cluster of CCS plant in the region ${ }^{x}$ (National Grid 2012).

\section{Revisiting the UKERC roadmap}

Our UKERC roadmap presented three schematics describing externalities affecting CCS implementation and milestones to establish CCS through demonstration era (the 'short-term') and into its commercialisation era (the 'long-term'). The influence of relevant policy and legal frameworks are described across UK, European and international scales. Notwithstanding the complexities of the UK CCS demo competition described above, progress has been made. The Energy Bill which came into force as the Energy Act 2008 provides the regulatory framework for the licensing of offshore $\mathrm{CO}_{2}$ storage and which is now excluded from requiring a marine licence under The Marine and Coastal Access Act of $2009^{\times i}$. Under new legislation, set to come into force in 2013, new plant must meet an Emission Performance Standard (EPS) of $450 \mathrm{gCO}_{2} / \mathrm{KWh}$, which allows gas but not coal plant without CCS (DECC, 2011).

The European Union Directive on the geological storage of carbon dioxide (EU Directive 2009/31/EC) sets out a comprehensive legal framework for CCS including provision for eventual transfer of responsibility for storage sites to the State. Although the Directive focuses on "environmentally safe geological storage of carbon dioxide $\left(\mathrm{CO}_{2}\right)^{\prime \prime}$ it also covers some aspects of capture and transport. In addition, CCS is also now fully provided for in phase 3 (beyond 2012) of the EU Emission Trading Scheme (ETS) as set out in Directive 2009/29/EC.

Internationally, progress within the UN Framework Convention on Climate Change (UNFCCC) towards was made in Durban 2011 at which the 'Durban Platform for enhanced action' was agreed around the decision to adopt "a universal legal agreement on climate change as soon as possible, and no later than 2015" (UNFCCC, 2011). While this does not yet establish legally binding emission targets, it has inspired renewed optimism after the failure to reach any such agreement in 2009 in Copenhagen or 2010 in Cancun. More specifically, the Durban meeting also resulted in eligibility for CCS under the Clean Development Mechanism ${ }^{\mathrm{xi}}$.

\section{The Global context}

In its global CCS Roadmap, the IEA suggested that 100 CCS projects by 2020 (increasing to 3400 by 2050) would be necessary to achieve an atmospheric $\mathrm{CO}_{2}$ concentration of $450 \mathrm{ppm}$ (with an assumed increase in fossil fuel consumption under its BLUE Map scenario) ref (IEA 2010). According to the Global CCS institute there are currently only 15 large scale CCS projects in operation (capturing $35.4 \mathrm{MTCO}_{2} \mathrm{pa}$ ), although there are a further 59 in planning (Institute 2011). Furthermore, a study to evaluate the global storage resources in the context of the IEA roadmap ambition suggests that there is wide gap between these targets (which could require 120Gt by 2050) and the available storage; the study estimates that approximately 50 sites could be operational by 2025 or, with the inclusion of $\mathrm{CO}_{2}$-EOR projects, 100 sites by 2028 (IEAGHG 2011).

\section{Unanswered questions}

Although the public perception of CCS has been widely recognised as a key factor, it is too early to say how the prospect of actual CCS plant will be received in the UK. Early research does not indicate that there is opposition to CCS in principle and, given sufficient and trusted information is available, there is evidence that the wider public may support its deployment, however concerns do exist (Roberts and Mander 2011). In the Netherlands, the Barendrecht CCS demonstration project (storage in onshore gas fields) has been postponed since 2009 following a growing body of 
opposition (Feenstra and Brunsting, 2010). In the UK, proposals for expansion of Kingsnorth met with opposition from climate campaigners and the anti-coal lobby ${ }^{\text {xiii }}$; however, although EON promoted the "carbon capture ready" (CCR) status of their proposals it is not clear how the inclusion of an operational CCS component would have affected opinion. Furthermore, at Hunterston in Scotland one of the sites of the proposed demonstration plants applying for the EU NER300 fund has already been subject to 21,000 objections to proposals for a new coal plant, with the local council recommending refusal of the planning application by the Scottish Parliament ${ }^{\text {xiv }}$. Opposition voiced against the Hunterston poposal focused on the fact that the carbon capture facility may only apply to part of the proposed $1.6 \mathrm{GW}$ plant, the unproven nature of CCS and the environmental impact both of further coal abstraction (including open-cast) and to the local environment ${ }^{\mathrm{xv}}$ (the proposed development extends over a Site of Special Scientific Interest (SSSI) ${ }^{\mathrm{xvi}}$ ).

Although there is potential for biomass energy with CCS (BECCS) to significantly reduce the emissions instensity of indivdual plant or even to deliver the potential for negative emissions, there remain concerns over whether sufficient biomass could be sustainably sourced, the level of confidence that can be attributed to the accounting of emissions from BECCS plant and whether sufficient opportunity exists in the UK (Gough and Upham 2011).

Despite significant progress in establishing a regulatory framework for CCS in the UK, considerable uncertainty remains over whether there will be sufficent incentives in the near term to achieve a low carbon energy system and generate investor confidence necessary to establish the technology. The CCC have proposed that the Government should underpin the carbon price to a guaranteed minimum level and to iron out fluctuations. However, the declared aim by the Secretary of State for Energy of establishing a "technology race" for a least cost option between renewables, CCS and nuclear power (DECC 2011) does not sit well with recommendations for a broad portfolio of options (for example, CCC 2010). Not only is a scenario in which a new technology such as CCS gains the greatest market share unlikely, it would not deliver a sustainable decarbonised future in the longer term.

\section{Are we nearly there?}

In the UK, while CCS will not be out of the demonstration era and ready for commercial deployment by 2015 , as optimistically suggested in the UKERC roadmap (Gough et al., 2010), considerable progress has been made. The first UK competition has successfully established knowledge exchange though the Front End Engineering Design with a first tranche of government funding ringfenced for CCS. The regulatory and liability frameworks are in place via the Energy Act 2008, the EU CCS Directive, the EU ETS Directive inter alia.

In 2012, results of the EU NER300 funding will be announced, and the UK is very well-placed to benefit from this scheme, representing 6 of the 12 applications; the UK Government has also declared its intention to set out its CCS programme this year. The large number of applications from the UK to the European funding competition provides an indication of the level of aspiration and activity in this area within the private sector. As the scientific arguments for increased efforts to mitigate against climate change stack up, the message for the urgency has not abated within the international community, via the UNFCCC, and the UK, via bodies such as the Government's Committee on Climate Change.

In our original roadmap paper we considered that "the UK is still well-placed to establish itself as a major player in bringing CCS to the mainstream" and we would argue that this is still the case. However, despite growing momentum, significant challenges remain and CCS will not be viable 
without Government backing and public funding. In the current economic climate that is clearly not something that can be guaranteed.

\section{References}

Committee on Climate Change (2008). Building a low-carbon economy - the UK's contribution to tackling climate change. Committee on Climate Change. London, The Stationary Office.

Committee on Climate Change (2010). The Fourth Carbon Budget - meeting emissions through the 2020's. Committee on Climate Change London, The Stationary Office.

Department of Energy and Climate Change. (2011). Digest of UK Energy Statistics 201. London, The Stationary Office.

Department of Energy and Climate Change. (2010). Pathways for 2050. London, The Stationary Office.

Department of Energy and Climate Change (2008). Climate Change Act 2008. Department of Energy and Climate Change. London, The Stationary Office: 103.

Global Carbon Capture and Storage Institute. (2011). The Global Status of CCS: 2011. Canberra, Australia, GCCSI.

Gough, C. (2008). "State of the art in carbon dioxide capture and storage in the UK: An experts' review." International Journal of Greenhouse Gas Control 2(1): 155-168.

Gough, C., S. Mander, et al. (2010). "A roadmap for carbon capture and storage in the UK." International Journal of Greenhouse Gas Control 4(1): 1-12.

Gough, C. and P. Upham (2011). "Biomass energy with carbon capture and storage (BECCS or BioCCS)." Greenhouse Gases: Science and Technology 1(4): 324-334.

Her Majesty's Treasury. (2011). Budget 2011. London, The Stationary Office.

International Energy Agency GHG (2011). Global storage resources gap analysis for policy makers. Cheltenham, IEA Greenhouse Gas Programme.

International Energy Agency (2010). Carbon capture and storage roadmap. Paris, IEA/OECD.

Office of Carbon Capture and Storage (2011). UK Carbon Capture and Storage (CCS) Commercial Scale Demonstration Programme. Delivering Projects 2-4 (Further Information). The Department of Energy and Climate Change. London, The Department of Energy and Climate Change.

Richards, P. (2012). Carbon Capture and Storage. London, House of Commons Library.

Roberts, T. and S. Mander (2011). "Assessing public perceptions of CCS: Benefits, challenges and methods." Energy Procedia 4(0): 6307-6314. 
Scottish Government (2010). Carbon Capture and Storage - a roadmap for Scotland. Edinburgh, Scottish Government and Scottish Enterprise.

\footnotetext{
i 2CO (2011) http://www.2coenergy.com/don_valley_power_project.html. Accessed 25 January 2012

ii http://www.guardian.co.uk/environment/2007/nov/11/carbonemissions.businessandmedia accessed 17th January

iii BP quits contest to build emissions plant By Ed Crooks, Rebecca Bream and Fiona Harvey 7 November 2008 Financial Times (FT.Com)

${ }^{\text {iv }}$ http://www.npowermediacentre.com/Press-Releases/RWE-npower-applies-to-build-UK-s-biggest-CarbonCapture-Pilot-Plant-b9d.aspx accessed 17th January 2012

${ }^{v}$ http://www.decc.gov.uk/en/content/cms/emissions/ccs/demo_prog/feed/feed.aspx accessed 17th January

${ }^{v i}$ Consortium leads carbon capture race, Sylvia Pfeifer and Fiona Harvey, 20 October 2010, Financial Times (FT.Com)

vii http://www.decc.gov.uk/en/content/cms/emissions/ccs/demo_prog/demo_prog.aspx accessed 17th January 2012

viii http://www.decc.gov.uk/en/content/cms/news/pn11_39/pn11_39.aspx

http://europa.eu/rapid/pressReleasesAction.do?reference=MEMO/10/549\&format=HTML\&aged=0\&language accessed $17^{\text {th }}$ January 2012

${ }^{x}$ Don Valley Power Carbon Capture and Storage (CCS) Project. http://www.nationalgrid.com/uk/EnergyandServices/NonRegs/CCS/Projects/DonValleyPower/

${ }^{x i}$ UCL Carbon Capture Legal Programme. http://www.ucl.ac.uk/cclp/ccsoffnational-UK.php

xii CCS enters the CDM at CMP 7.

http://www.globalccsinstitute.com/community/blogs/authors/markbonner/2011/12/10/ccs-enters-cdm-cmp7

xiii Energy: Climate camp: 1,400 police prepare for the unexpected: How to get there John Vidal, Environment editor 9 August 2008; The Guardian

xiv Communities Against New Coal at Hunterston, “North Ayrshire Council Say NO"

http://www.conchcampaign.org/ Accessed 25 January 2012

${ }^{x v}$ Hunterston coal power plan submitted to ministers, BBC News 2 June 2010, http://www.bbc.co.uk/news/10208275 Accessed 25 January 2012

xvi http://www.ayrshirepower.co.uk/faqs Accessed 25 January 2012
} 